\title{
Analyzing Chinese English by the functional equivalence theory
}

\author{
Zhao Hui Min ${ }^{1, a}$ \\ ${ }^{1}$ Bohai university, Jinzhou, 121013 China \\ azhaihuimin@126.com
}

Keywords: Functional equivalence theory; Chinese English; Chinese characteristics; English translation skills; translation strategies.

\begin{abstract}
Over the past few years, with China's rising international status, the international arena has a more right to speak. The emergence of a large number of words with Chinese characteristics has played an important role in China's propaganda. When the eastern and Western cultures are blended, it is the most important task for the translators to spread the Chinese and Western culture to the western countries. The essence of translation is to translate one language into another, which is communicated to the audience. Translation theory is often divided into translation and interpretation, translation and translation skills such as transliteration, literal translation and free translation techniques, analysis of the basic skills of interpreting translation skills for the purpose of this paper is to reference the translation. The famous American translation theorist Nida "s Functional Equivalence Based on the theory, he believes that between the source language and the target language can be achieved at four levels of equivalence: vocabulary equivalence, syntactic equivalence, stylistic equivalence and textual equivalence. This paper analyzes the application of translation methods such as transliteration, literal translation and free translation from four levels of equivalence, and explores the translation of Chinese characteristics into English This paper discusses the English translation of Chinese tourism texts from the perspective of functional equivalence.
\end{abstract}

\section{Introduction}

Tourism has become an important industry undergoing rapid growth on a global scale, and China is of no exception. With the rapid development of China's economy and its opening-up effort, more and more foreigners begin to be interested in this mysterious eastern country, which is famous for its beautiful scenic spots as well as abundant cultural relics. To better understand China, the most popular and effective way they choose is to travel in China. It should be acknowledged that there are many well translated tourism texts, which contribute to the spread of Chinese culture; however, the quality of some English versions of tourism texts are still far from satisfactory. It should be pointed out here is that this kind of problem cannot be ignored, for mistakes in translated tourism texts, will affect publicity[1], or even spoil the image of our country. Chinese tourism texts cover all the materials concerning Chinese tourism industry and tourism resources. The focus is brochures and pamphlets for tourism attractions, guidebooks of cities or countries and tourist advertisements introducing scenic spots or cultural relics in China. In addition, some data has been downloaded from the Internet. A great number of examples picked from these sources, successfully translated ones as well as unsuccessfully translated ones, are employed in the thesis. Guided by FE theory, several translation principles are proposed. The research methods used in this paper are mainly comparative analysis and theoretical analysis, for example, the contrastive analysis between TL readers and SL readers [2].

\section{The key theoretical analysis}

Introduction to the development of FE Theory.

Eugene A. Nada, a distinguished American translation theorist as well as a linguist, was the most influential one among the contemporary theorists in the field of translation in the last century. He made great contribution to the translation studies in the western countries. Before his theory was 
introduced into China in the 1980s, people mainly focused attention on traditional Chinese translation principles, especially Yan Fu's three-character principle of translation, i.e. faithfulness, expressiveness and elegance. Since Nada's theory is grounded solidly on contemporary developments of linguistics, communication theory, information theory, semiotics and anthropology, Chinese translation scholars take great interest in his theory(ma hui juan, 2003:1).From 1945 to 1997, Nada wrote more than 190 articles and published 40 books. "Functional equivalence" is one of Nada's major contributions to translation study. It comes from the concept of "dynamic equivalence" which is postulated in Toward a Science of Translating published in 1964 and considered as an important milestone in Nada's translation research.

\section{Dynamic Equivalence Theory.}

The essential idea of "dynamic equivalence" was first mentioned by Nada in his article "Principles of Translation as Exemplified by Bible Translates” written in 1959. In his attempt to define translating, Nada writes: A definition of translation...could be stated as follows: "Translating consists in producing in the receptor language the closest natural equivalent to the message of the source language, first in meaning and secondly in style."In this definition, there are three essential terms: "closest", "natural" and "equivalent". Among the three terms, "equivalent" points to the source-language message, "natural" the receptor language, and "closest" binds the two orientations together on the basis of the highest degree of approximation. The concept of "dynamic equivalence" is postulated in Toward a Science of Translating. In Toward a Science of Translating Nada distinguishes two types of equivalence: “dynamic equivalence”and“formal equivalence”. In such a translation (dynamic equivalent translation) one is not so concerned with matching the receptor-language message with the source message, but with the dynamic relationship, that the relationship between receptor and message should be substantially the same as that which existed between the original receptors and the message. (Nada, 1964:161) Correspondingly, "Formal equivalence" is basically source-oriented. In such a translation, the translator attempts to "reproduces as literally and meaningfully as possible the form and content of the original" (Nada, 1964:165) , and the reader is permitted to "identify himself as fully as possible with a person in the source-language context, and to understand as much as he can of the customs, manners, thought, and means of express" (Nida, 1964:159). In other words, a formal equivalent translation is a literal but meaningful translation, which usually requires footnotes in order to make the text fully comprehensible [3].

\section{Functional Equivalence.}

In his From One Language to Another (Nada, 1986), Nada changed the term to "functional equivalence”. But essentially there is not much difference between the two concepts. He adopts the term "functional equivalence" to stress the concept of function and to avoid misunderstanding of the term "dynamic" which is mistaken by some persons for something in the sense of impact (Nada, 1993:124). Nada holds that 'the terms 'function' and 'functional' seem to provide a much sounder basis for talking about translation as a form of communication, since the focus is on what a translation does or performs." He notes that a useful way to think and talk about functional equivalence is by means of isomorphs. A lack of functional equivalence can be described in terms of a failure to provide isomorphic limits. (Nada, 2001:125)In his book Language, Culture and Translation (Nida, 2000), Nada wrote: Such a view of functional equivalence implies different degrees of adequacy from minimal to maximal effectiveness on the basis of both cognitive and experiential factors .A minimal, realistic definition of functional equivalence could be stated as "the readers of a translated text should be able to comprehend it to the point that they can conceive of how the original readers of the text must have understood and appreciated it." Anything less than this degree of equivalence should be unacceptable. A maximal, ideal definition could be stated as "The readers of a translated text should be able to understand and appreciate it in essentially the same manner as the original readers did." The maximal definition implies a high degree of language-culture correspondence between the 
source and target languages and an unusually effective translation so as to produce in receptors the capacity for a response very close to what the original readers experienced.

\section{Researches on the Translation of Chinese Tourism Texts}

\section{Research on Theory.}

In order to promote the local tourism, government at all levels in China has been producing an increasing amount of English tourist texts most of which are translated from Chinese. However owing to great cultural differences between the East and the West the translation quality is far from satisfactory. How to solve the problems attracts much attention from the translation world. In the 1980s, Chinese scholars unexplored how to translate tourist texts from different angles. Lai Yu (1986:23-25) mainly emphasizes the translator's responsibility. According to him the translator should first fully understand the source text; secondly the translator should make the English version easy for western readers to understand; thirdly the translator should be able enough to provide perfect translations. Chen Gang (1987:26-29) deems that the tour guide as well as the translator should have a good command of cultural background about scenic spots and psychological factors of the tourists. To some extent, in the 1980s, the faithfulness to the original was given high priority. In the 1990s, some scholars began to study tourist text translation from cultural perspectives. Min Daylong (1992:32-35) provides some strategies for the translation of names of scenic spots. Liu Huimei and Yang Shoukang (1996:10-14) stress cultural differences in psychology, customs, religions, etc. Translation scholars during this period mainly discussed strategies employed in the tourist text translation. Some of them touch upon reader's acceptance.

\section{Tourism Texts.}

Tourism texts include various texts concerning tourism industry. Tourism is not a single entity. It consists of many different kinds of enterprises that offer different services to the traveler. Hence, travel agency and government all play a part in the development of tourism. That is to say all the textual information concerning tourism resources tourism products tourism statistics tourism research tourism education as well as transportation, accommodations, food, shopping and entertainment can be defined as tourism texts(chengang, 2004:309-310). In addition, the mass media including newspapers, magazines, televisions and the internet is another major channel for tourism advertising.

\section{Classification of Tourism Texts.}

English used in the services of miscellaneous sectors of tourism industry includes all introductions in English concerning travel agency, travel services, tourist attractions at home and abroad, natural or man-made landscapes, catering culture in tourism, shopping in tourism, transportation in tourism, regulations in tourism, etc. These introductions are original in English or translation from Chinese into English (yuan xian quan, 1999). Generally speaking, Chinese tourism texts can be classified into the following three categories: 1) Brochures and pamphlets for tourism attractions Brochures and pamphlets for tourism attractions provide a detailed introduction to natural wonders or historical relics, which aim to arouse the reader's interest, provoking an impulse toward the final traveling action. 2) Guidebooks of cities or countries Introduction to a country or a city generally contain basic information such as geographical and climate conditions, races, places of interest, culture, history and customs. 3) Tourist advertisements Tourist advertisements include advertisements on telephone directory, bulletin board, magazine, newspaper and television, etc. Such advertisements impress the tourists with their delicate designs and attractive pictures of the tourist attractions. Brochures and pamphlets are the most typical among the three categories. Most of the samples in this thesis are taken from brochures and pamphlets for scenic spots [4]. 


\section{Basic Functions of Tourism Texts.}

Language has to serve various purposes as there are different types of occasions for using it. Chinese tourism texts are tailored to a selected group of potential customers. The ultimate goal of Chinese tourism texts is to persuade potential customers to buy certain tourism products. These texts intend not only to provide information for customers, but also to sustain their interest, and eventually to convince them to visit the tourism attractions. Thus, we can conclude that good Chinese tourism texts should be informative, attractive and persuasive. 1) The informative Function As Professor Hu Zhuanglin observes, "Language serves an informative function when it is used to tell what the speaker believes, to give information about facts or to reason things out." Apparently, being informative is a basic requirement for Chinese tourism texts. It means that they should supply sufficient information on tourist destinations. The function at the stage of consumer's awareness. Before deciding which tourism product to buy, the potential tourist often tries to obtain sufficient information on various tourism products. Then he/she will be able to know more about the historical, cultural or natural value of a specific tourist destination. Besides, the potential tourist also searches for information on transportation and accommodation, which are also provided in Chinese tourism texts. In the following example, information on opening hours, location, phone numbers and web sites are supplied, which makes potential tourists feel that their tour would be safe and comfortable.

\section{The Development of Functional Equivalence Theory in Translation of Tourism Texts}

\section{Criteria for Translations of Chinese Tourism Texts.}

The prosperous international tourism industry in China gives rise to the needs to translate all kinds of tourism texts in large quantities and of good quality for the simple reason that average foreign visitors don't know Chinese and need to refer to well- translated versions in their own language so as to arouse their interests in China and provide them with necessary travelling formation. As English is a global language large quantities of tourism texts have been translated into English in an attempt to attract as many visitors as possible. C-E translation of tourism texts has become very important for the development of China's international tourism industry. In translating tourism materials, both cultural uniqueness and readability are to be ensured with a view to promoting Chinese culture. Then how to preserve in the Translation as much as possible those specific cultural elements and at the same time ensure readability is headache to many translators.

\section{Natural Language.}

The quality of naturalness is central to an F-E translation, as seen in Nada and Taber's definition, "Translating consists in reproducing in the receptor language the closest natural equivalent of the source language message, first in terms of meaning and second in terms of style” . (Nida\&Taber, 1969: 14). An FE translation may be described as "one concerning which a bilingual and bicultural person can justifiably, 'that is just the way we would say it' ”. That is, when English-speaking readers read tourism texts translated from Chinese, they should not have the sense that they are reading a translation. Nada and Taber once said that "good translation does not sound like a translation”. (Nada \& Taber, 1969: 14).An FE translation should not exhibit any trace of awkwardness or strangeness in its grammatical and stylistic forms. That is, the translator shall follow grammatical rules of English rather than impose the Chinese grammar to English. However, Nada also admits that no translation is supposed to eliminate all traces of foreign setting and many difficult themes and accounts may not be naturalized by the process of translating such as when the source and receptor language represent very different cultures.

\section{Arousing Equivalent Responses.}

Functional equivalence is defined by Niacin terms of the degree to which the receptors of the message in the receptor language respond to it in substantially the same manner as the receptors in the source language.” (Nida,2004:24).It can be interpreted in such a way that target language receptors must not 
only know how the original receptors must have understood the content of the text, but they should also be able to appreciate some of the impact and appeal which such a text must have had for the original receptors. In other words, priority shall be given to target receptor's intelligibility. However, intelligibility is not measured merely in terms of whether the words are understandable and the sentences grammatically constructed, but in terms of the total impact the message has on the one who receives it.(Nida,2004:22). That is, the response of the source-text readers and the response of the target-text readers should be equivalent. This response can be never identical, for the cultural and historical settings are too different, but there should be a high degree of equivalence of response, or the translation will fail to accomplish its purpose (Nada, 2004:24). However, there are a number of fundamental problems involved in judging a translation by the equivalence of "reader's response". In the first place, it is often very difficult to determine how the original readers comprehend the text, and in the second place, it is frequently impossible to evaluate effectively the responses of those who read a translated text. Therefore, it requires that the translator presumes the TL reader's response as much correctly as possible [5].

\section{Summary}

in the practice of translating Chinese tourism texts, the importance and difficulty lie in the transfer of cultural messages. Abundant Chinese cultural specific messages are contained in Chinese tourism texts. Chinese readers usually have no difficulty in understanding them because they share the some cultural background with the author. But it is not the case for western readers who are not familiar with Chinese culture and are different from Chinese people in various aspects, such as customs, aesthetic standards, and ethic values. However, cultural messages in tourism materials should not be ignored in translation as they help to spread Chinese culture. It is found by the author that cultural contents in Chinese tourism texts mainly contain: names of tourist sites, dynasties, characters, places, historical events, Chinese unique resources and classic quotations. These cultural contents should be put great emphasis to by the translator.

\section{Acknowledgements}

The province social science fund :L15DWW005.

\section{References}

[1] Yang Jianhua, Gao Tianyu, re read the "functional equivalence" [J]. foreign language teaching from the translation operation process. 2007 (06).

[2] Ma Biao. "The first time" of the translation and the use of [J]. foreign language journal. 2005 (03).

[3] Zhang Yisheng. Contemporary words "zero X" word family of Chinese word building -- the contemporary evolution of the motivation of [J]. language application. 2003 (01).

[4] Tang Xiangjin. Chinese Loanwords in English language and cultural factors [J]. Journal of Xi'an College of Foreign Languages. 2000 (03).

[5] Xie Yan. "Chinese and English mixed code" - modern language shock wave [J]. English knowledge. 2000 (04). 